\title{
PELATIHAN AFTER EFECTS UNTUK MENINGKATKAN KREATIFITAS SISWA JURUSAN MULTIMEDIA SMK MUHAMMADIYAH 2 PEKANBARU
}

\author{
Yoyon Efendi ${ }^{1}$, Lusiana ${ }^{2}$, Rometdo Muzawi ${ }^{3}$, Karpen ${ }^{4}$, Wirta Agustin ${ }^{5}$ \\ 1, 2,3,4,5STMIK Amik Riau, Pekanbaru, Indonesia \\ email: 1yoyonefendi@stmik-amik-riau.ac.id, 2lusiana@stmik-amik-riau.ac.id, \\ 3rometdomuzawi@stmik-amik-riau.ac.id, ${ }^{3}$ karpen@stmik-amik-riau.ac.id, \\ 5wirtaagustin@stmik-amik-riau.ac.id
}

\begin{abstract}
Abstrak: After Effects salah satu software efek digital visual, grafis gerak, dan aplikasi compositing yang dikembangkan oleh Adobe Systems dan digunakan dalam proses pasca produksi pembuatan film dan produksi televisi. After Effects dapat digunakan untuk memasukkan, melacak, rotoscoping, compositing dan animasi. Kegiatan pelatihan ini ditujukan pada siswa -siswi SMK Muhammadiyah 2 Pekanbaru jurusan Multimedia. Siswa diberikan materi dari konsep pengembangan multimedia, pengenalan after effects, pengenalan tool, project opening, animasi teks dan mini kompetisi multimedia. Dengan adanya pelatihan ini akan meningkatkan kreatifitas multimedia untuk menjadi bekal siswa dalam menghadapi magang dan Ujian Keahlian Kompetensi (UKK).
\end{abstract}

Kata Kunci: After Effects, Multimedia, SMK Muhammadiyah 2 Pekanbaru

Abstract: After Effects is a digital visual effects software, motion graphics, and compositing application developed by Adobe Systems and used in the post-production process of filmmaking and television production. After Effects can be used for inserting, tracing, rotoscoping, compositing and animation. This training activity is aimed at students of SMK Muhammadiyah 2 Pekanbaru majoring in Multimedia. Students are given material from the concept of multimedia development, introduction to after effects, introduction to tools, project opening, text animation and multimedia mini competition. With this training, it will increase multimedia creativity to equip students to face internships and the Competency Skills Exam (UKK).

Keywords: After Effects, Multimedia, SMK Muhammadiyah 2 Pekanbaru

\section{Pendahuluan}

Multimedia merupakan suatu sarana (media) yang didalamnya terdapat perpaduan (kombinasi) berbagai bentuk elemen informasi, seperti teks, graphics, animasi, video, interaktif maupun suara sebagai pendukung untuk mencapai tujuannya yaitu menyampaikan informasi atau sekedar memberikan hiburan bagi target audiens-nya. Multimedia sering digunakan dalam dunia hiburan seperti game. Definisi multimedia beragam tergantung lingkup aplikasi serta perkembangan teknologi multimedia itu sendiri(Diah \& Nita, 2018)

Kata multimedia itu sendiri berasal dari kata multi (Bahasa Latin) yang berarti banyak dan katamedia (Bahasa Latin) yang berarti sesuatu yang dipakai untuk menyampaikan sesuatu. multimedia didefinisikan sebagai penyampaian informasi secara interaktif dan terintegrasi yang mencakup teks, gambar, suara,video atau animasi(Lestari, 2013).

Multimedia dapat dikategorikan menjadi 2 macam, yaitu mulitimedia linier dan multimedia interaktif. Multimedia linier merupakan suatu multimedia yang tidak dilengkapi dengan alat pengontrol apapun yang dapat dioperasikan oleh pengguna. Multimedia ini berjalan sekuensial (berurutan / lurus), contohnya : TV dan film. Sedangkan Multimedia interaktif 
merupakan kumpulan dari beberapa media seperti tesk, gambar, audio, video, dan animasi yang bersifat interaktif yang digunkan untuk menyampaikan informasi(Nopriyanti \& Sudira, 2015). Contohnya seperti aplikasi game. Multimedia interaktif menggabungkan dan mensinergikan semua media yang terdiri dari teks, grafik, audio, dan interaktivitas (rancangan).

Aplikasi multimedia merupakan aplikasi yang dirancang serta dibangun dengan menggabungkan elemen-elemen seperti : dokumen, suara, gambar, animasi serta video. Pemanfaatan dari aplikasi multimedia dapat berupa company profile, video untuk tutorial, e-Learning, maupun Computer Based Training. Di antaranya seperti berikut: After Effects, Adober Premiere, Adobe Audition dan Macromedia Flash MX 2004.

Adobe After Effects adalah produk piranti lunak yang dikembangkan oleh Adobe Systems Incorporated asal Amerika, digunakan untuk film dan pos produksi pada video(Desca Refita Putri, 2017). Adobe After Effect lebih mudah diaplikasikan dan hasilnya pun tidak kalah bahkan mengungguli aplikasi lain.(Dimas Ismail Hasan, 2018). Proses produksi atau pembuatan animasi menggunakan adobe after effect memungkinkan segala bentuk animasi dapat dibuat sesuai dengan keinginan pembuat dikarena pemnbuatan karakter atau objek, pergerakan karakter atau objek tidak batasi seperti aplikasi animasi lain yang hanya bisa bergerak sesuai dengan efek animasi yang telah ditetapkan aplikasi(Y. A. Akbar \& Yuliawan, 2018).

After Effects salah satu software efek digital visual, grafis gerak, dan aplikasi compositing yang dikembangkan oleh Adobe Systems dan digunakan dalam proses pasca produksi pembuatan film dan produksi televisi. After Effects dapat digunakan untuk memasukkan, melacak, rotoscoping, compositing dan animasi. After effects pun bukan software video editing, sehingga untuk merangkai video dengan durasi relative panjang perlu menggunakan Adobe Premiere. after effect pun bukan software animasi 3D, sehingga untuk membuat animasi 3D lebih powerfull akan lebih baik jika menggunakan 3D Studiomax.3.1(T. . A. Akbar \& Munandar, 2019)

Kegiatan pelatihan ini ditujukan pada siswa -siswi SMK Muhammadiyah 2 Pekanbaru jurusan Multimedia. Siswa diberikan materi dari konsep pengembangan multimedia, pengenalan after effects, pengenalan tool, project opening, animasi teks dan mini kompetisi multimedia.

Dengan adanya pelatihan ini akan meningkatkan kreatifitas multimedia untuk menjadi bekal siswa dalam menghadapi magang dan Ujian Keahlian Kompetensi (UKK).

Berdasarkan paparan pada analisa situasi masalah yang dihadap dapat diidentifikasi sebagai berikut: Rendahnya pengetahuan siswa dalam After Effects, Rendahnya pengetahuan siswa dalam Multimedia dan Animasi. Dan Kurangnya pengetahuan siswa dalam penggunaan animasi dan Opening project After Effects.

Tujuan yang ingin di capai dalam kegiatan ini diantaranya adalah : Siswa mampu memahami konsep pengembangan multimedia. Siswa mampu mengimplementasikan animasi dan teks pada After Effects. Siswa mampu menyelesaikan mini kompetisi project 
Opening video animasi After Effects. Dan Siswa mampu meningkatkan kreatifitas multimedia

Adapun manfaat kegiatan pengabdian masyarakat ini adalah sebagai berikut : Kegiatan ini diharapkan dapat memacu kreatifitas multimedia siswa dengan baik dan benar. Dan Kegiatan ini diharapkan membuat siswa dapat menyelesaikan mini kompetisi project animasi After Effects.

\section{Metode}

Teknik yang digunakan dalam menyampaikan materi pelatihan adalah Presentasi, pratikum, mini kompetisi dengan menggunakan alat bantu berupa komputer multimedia, laptop, LCD dan light pen. Kegiatan pelatihan ditujukan untuk siswa-siswi SMK Muhammadiyah 2 Pekanbaru yang dilaksanakan di Labor Multimedia SMK Muhammadiyah 2 Pekanbaru.

Pendekatan yang digunakan pada pengabdian masyarakat di SMK Muhammadiyah 2 Pekanbaru adalah Materi di lengkapi dengan modul, project mobile, video tutorial dan studi kasus. Pemecahan Masalah melalui presentasi konsep dan praktikum after effects untuk mendukung pemahaman peserta pelatihan di dampingi oleh Tutor yang berpengalaman.

Pendekatan cara pemecahan msalah yang dilakukan yaitu:

1. Memberikan motivasi kepada peserta pelatihan

2. Menggali pengetahuan peserta akan media pembelajaran (pre-test)

3. Konsistensi materi pelatihan

4. Mengajak peserta untuk aktif dalam pelatihan

5. Pratikum sebagai penerapan After Effects

6. Evaluasi pelatihan sebagai tolak ukur hasil luaran(post-test)

Pelatihan tersebut diberikan langsung oleh tim dosen STMIK Amik Riau di SMK Muhammadiyah 2 Pekanbaru. Media pelatihan yang digunakan adalah sebagai berikut:

1. Media proyektor dan laptop untuk menampilkan secara visual mengenai materi pelatihan yang akan dissampaikan.

2. Laser pointer, yang digunakan untuk memberikan kesan lebih interaktif dalam menyajikan bahan pelatihan bagi guru, sehingga lebih dapat memunculkan semangat bagi guru dalam kegiatan pelatihan.

3. Modul pratikum dilengkapi contoh - contoh studi kasus.

\section{Hasil dan Pembahasan}

Kegiatan pelatihan yang telah dilaksanakan di SMK Muhammadiyah 2 Pekanbaru ini telah dilakukan dengan hasil yang baik. Siswa telah diberi materi tentang pengantar multimedia, pengenalan After Effects, pengenalan tool dan menu After Effects, pratikum teks dan Animasi After Effects, mini kompetisi opening project After Effects dan evaluasi hasil sehingga siswa-siswi menguasai materi yang disampaikan dengan sangat baik. 


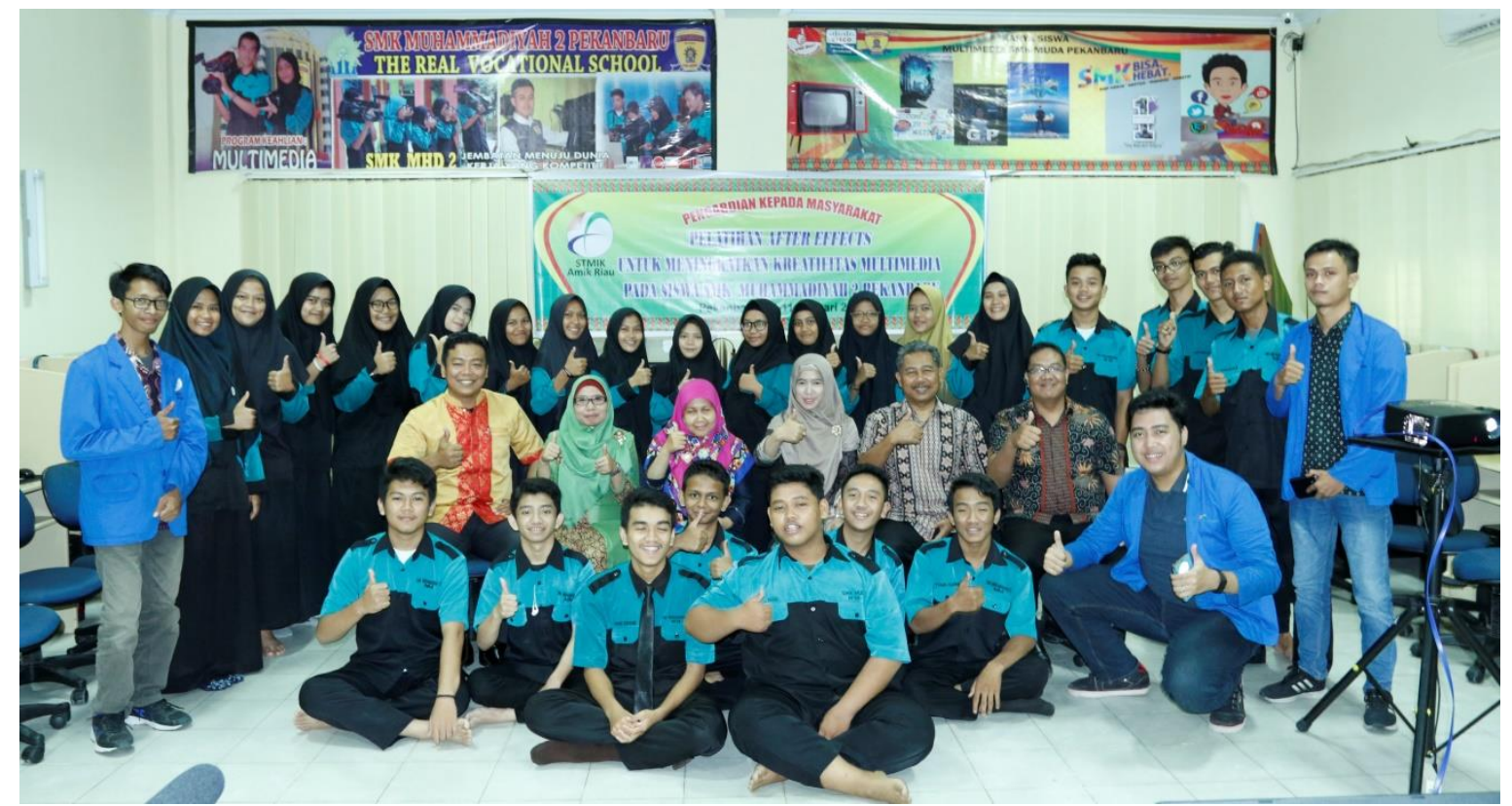

Gambar 1. Foto bersama peserta dan tim dosen

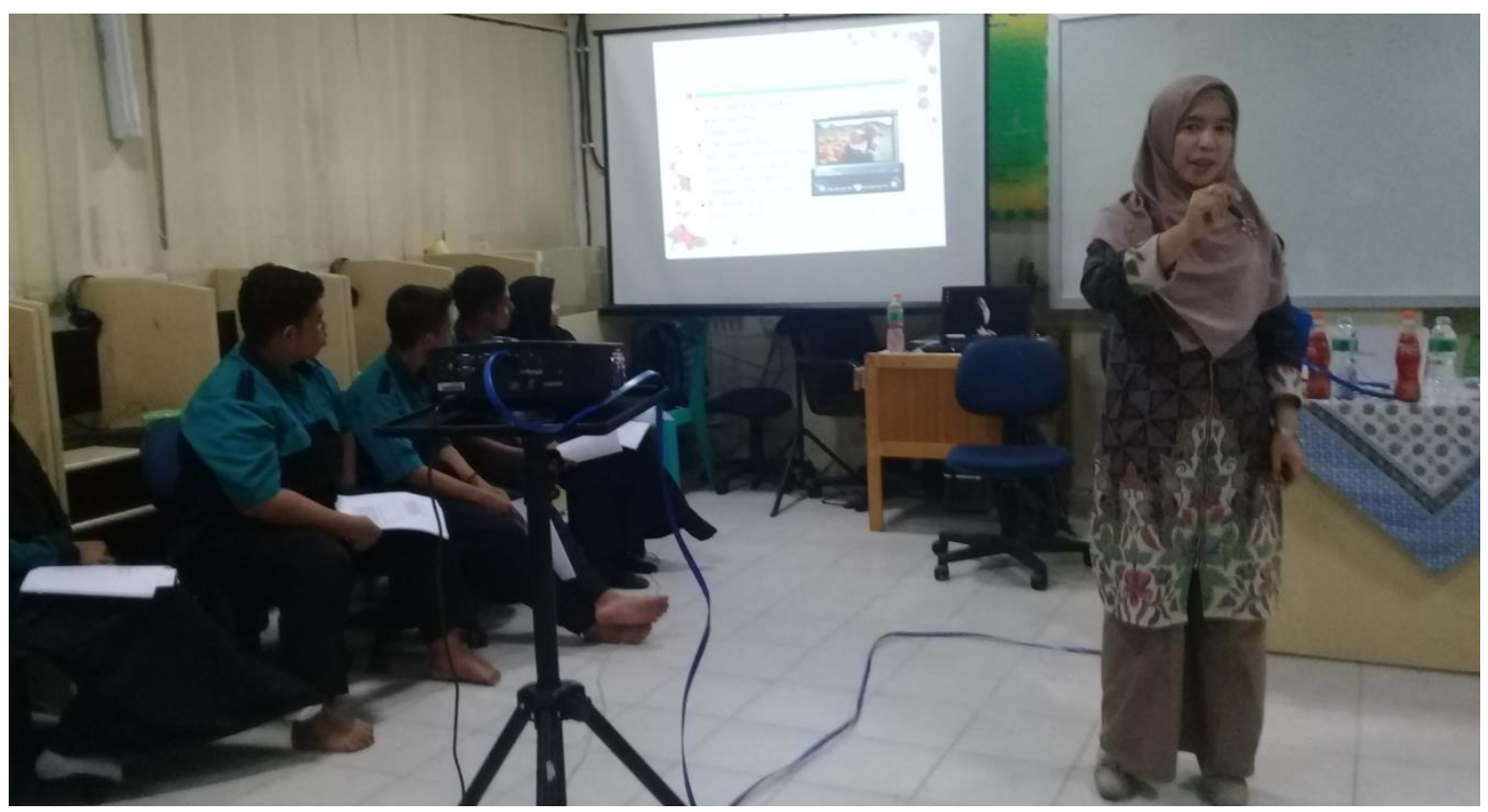

Gambar 2. Tim dosen memberikan materi 


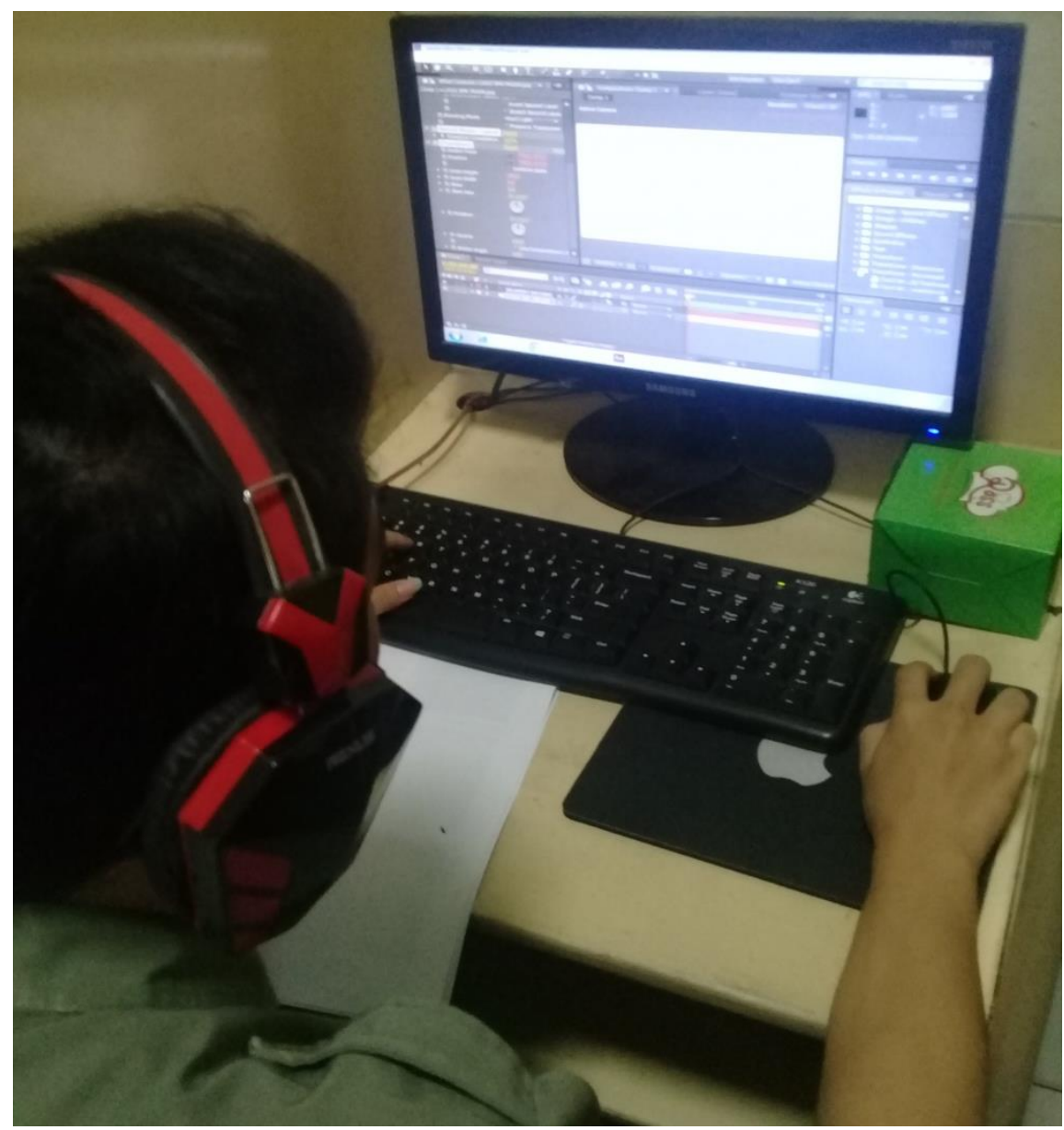

Gambar 3. Praktikum after Effect dilakukan dilaboratorium

Sejumlah 25 orang peserta yang menghadiri pengabdian kepada masyarakat "Pelatihan After Effects untuk Meningkatkan Kreatifitas Multimedia pada SMK Muhammadiyah 2 Pekanbaru". Setelah pelaksanaan pelatihan, adanya peningkatan pengetahuan mereka secara signifikan. Terlihat semua siswa mampu menyelesaikan tugas pratikum yang diberikan. Oleh sebab itu diharapkan peserta pelatihan dapat memanfaatkan pengetahuan ini untuk mampu mengembangkan diri dalam Multimedia terutama After Effects.

Hasilnya terjadi peningkatan pengetahuan dan keahlian siswa-siswi menggunakan After Effect melalui Pre-test dan Post-test seperti terlihat pada tabel 1 sebagai berikut:

Tabel 1. Tabel Pre-test dan post-test peserta workshop

\begin{tabular}{clclc}
\hline No. & \multicolumn{2}{c}{ Pre-Test } & \multicolumn{2}{c}{ Post-Test } \\
\hline & Jawaban & Jumlah & Jawaban & Jumlah \\
\hline 1 & Benar 1 & 3 & Benar 1 & 0 \\
2 & Benar 2 & 2 & Benar 2 & 0 \\
3 & Benar 3 & 4 & Benar 3 & 0 \\
4 & Benar 4 & 5 & Benar 4 & 0
\end{tabular}




\begin{tabular}{cllll}
5 & Benar 5 & 6 & Benar 5 & 0 \\
6 & Benar 6 & 5 & Benar 6 & 0 \\
7 & Benar 7 & 0 & Benar 7 & 15 \\
8 & Benar 8 & 0 & Benar 8 & 3 \\
9 & Benar 9 & 0 & Benar 9 & 4 \\
10 & Benar 10 & 0 & Benar 10 & 3 \\
\cline { 2 - 4 } & & 25 & & 25
\end{tabular}

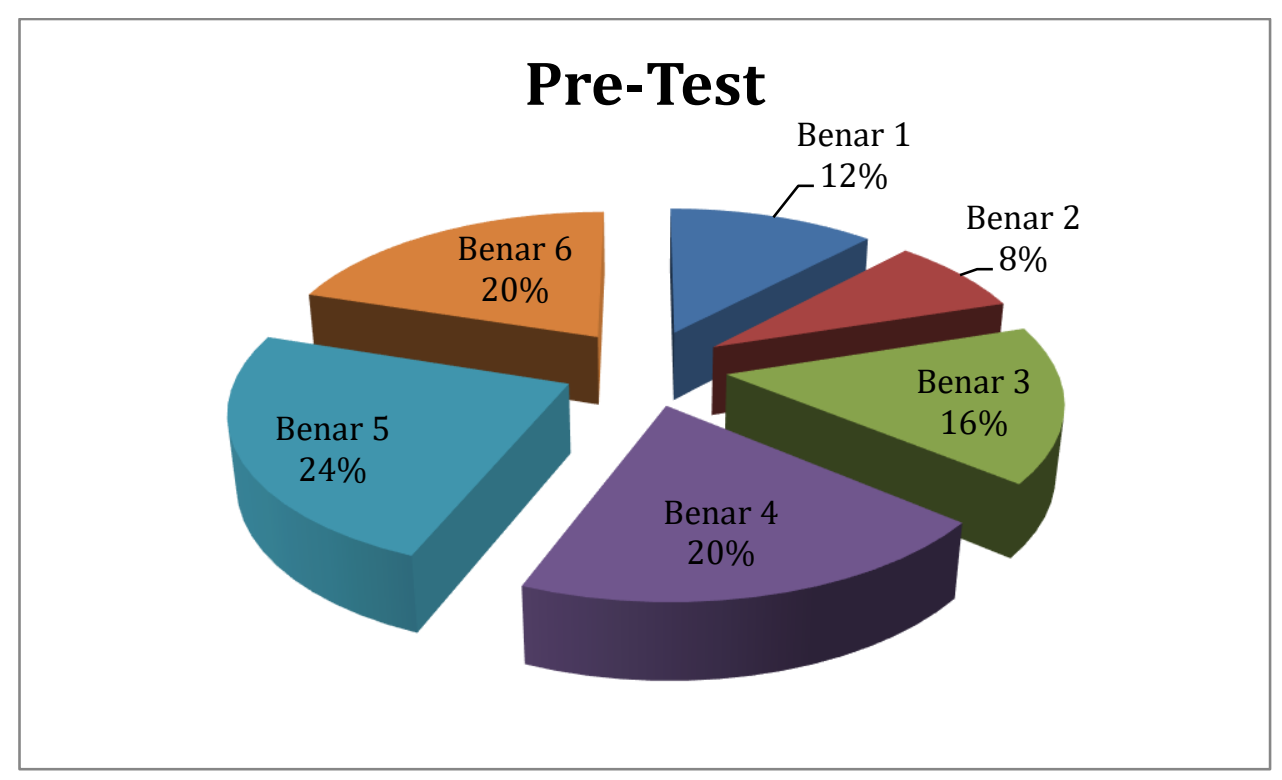

Gambar 4. Grafik Pre-test

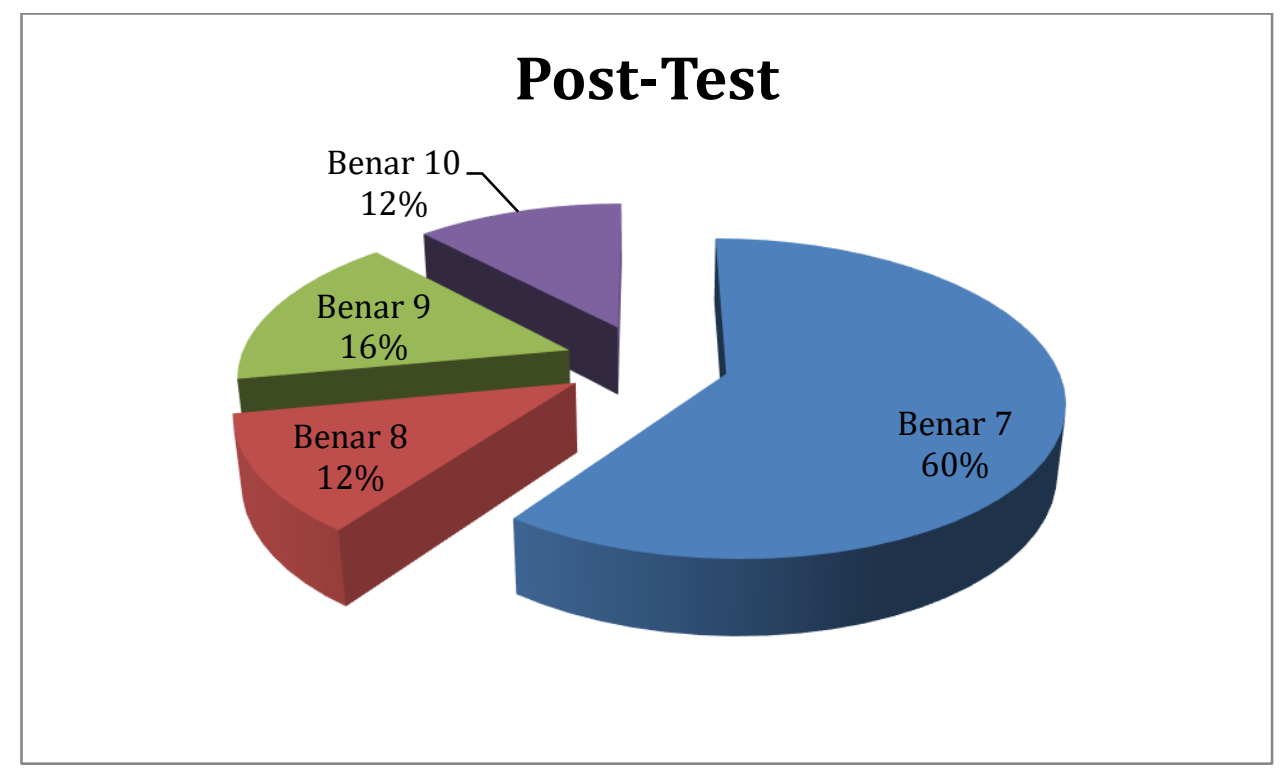

Gambar 5. Grafik Post-test 


\section{Kesimpulan}

Berdasarkan hasil pelaksanaan kegiatan yang telah dilakukan, dapat ditarik kesimpulan sebagai berikut:

1. Dengan adanya pelatihan ini siswa dapat mengetahui After Effects.

2. Siswa menerapakan ilmu dan pengetahuan After Effects pada saat pratikum di sekolah, magang dan Ujian Keahlian Kompetisi (UKK).

3. Dengan adanya pelatihan ini siswa-siswi dapat mengembangkan dan meningkatkan Kreatifitas Multimedia.

\section{Ucapan Terimakasih}

Terimakasih diucapkan kepada Kepala Sekolah SMK Muhammadiyah 2 Pekanbaru, terutama guru-guru Jurusan Multimedia. Kepada LPPM STMIK Amik Riau yang sudah mendukung terlaksananya Pengabdian ini. Selain itu juga tim dosen dan mahasiswa sebagai pelaksana kegiatan. Serta peserta dari siswa-siswi dari jurusan multimedia SMK Muhammadiyah 2 Pekanbaru.

\section{Daftar Pustaka}

Akbar, T. . A., \& Munandar, A. (2019). Perancangan Video Profil Prodi S-1 Teknik Informatika Universitas Ubudiyah Indonesia Sebagai Media Informasi Dan Promosi Berbasis Visual Effect. Journal of Informatics and Computer Science, 4(2), 57. https://doi.org/10.33143/jics.vol4.iss1.531

Akbar, Y. A., \& Yuliawan, K. (2018). Animasi Infografis Produk Asuransi Bumiputera Manokwari Menggunakan Adobe After Effect CS 6. Jurnal Teknologi Dan Ilmu Komputer Prima (JUTIKOMP), 1(1), 5-10. https://doi.org/10.34012/jutikomp.v1i1.228

Desca Refita Putri, Y. (2017). Pembuatan Motion Graphics sebagai Media Sosialisasi \& Promosi untuk Aplikasi Mobile Trading Online Mandiri Sekuritas. KOPERTIP: Jurnal IImiah Manajemen Informatika Dan Komputer, 1(2), 85-92. https://doi.org/10.32485/kopertip.v1i02.16

Diah, I., \& Nita, S. (2018). Pembuatan Video Sebagai Media Pembelajaranuntuk Meningkatkan Pemahaman Mahasiswa. DoubleClick: Journal of Computer and Information Technology, 1(2), 68-75. http://e-journal.unipma.ac.id/index.php/doubleclick

Dimas Ismail Hasan, A. F. (2018). Aplikasi Adobe After Effect Cs 4 Dalam Pembuatan Video. Jurnal Aplikasi Bisnis.

Lestari, A. S. (2013). PEMBELAJARAN MULTIMEDIA. Jurnal A/-Ta'dib, 6(2), 84-98.

Nopriyanti, N., \& Sudira, P. (2015). Pengembangan multimedia pembelajaran interaktif kompetensi dasar pemasangan sistem penerangan dan wiring kelistrikan di SMK. Jurnal Pendidikan Vokasi, 5(2). https://doi.org/10.21831/jpv.v5i2.6416 